Milon, A.; Bulliard, J.L. ; Vuilleumier, L. ; Danuser, B. ; Vernez, D. Estimating the contribution of occupational solar ultraviolet exposure to skin cancer. British Journal of Dermatology, 170(1) :157-164, 2014.

\begin{tabular}{|l|l|}
\hline Postprint version & Final draft post-refereeing \\
\hline Journal website & $\underline{\text { http://onlinelibrary.wiley.com/journal/10.1111/(ISSN)1365- }}$ \\
\hline Pubmed link & $\underline{\text { http://www.ncbi.nlm.nih.gov/pubmed/23980934 }}$ \\
\hline DOI & $\underline{10.1111 / \text { bjd.12604 }}$ \\
\hline
\end{tabular}




\section{Estimating the contribution of occupational solar UV exposure to skin cancer}

Running title: Contribution of occupational UV exposure to skin cancer

$\mathrm{Nb}$. of words: 4123

Nb. of tables: 3

$\mathrm{Nb}$. of figures: 3

Antoine Milon'1, Jean-Luc Bulliard², Laurent Vuilleumier³, Brigitta Danuser¹, David Vernez ${ }^{1 \star}$

1 Institute of Work and Health (IST), University of Lausanne and Geneva, Lausanne, Switzerland.

${ }^{2}$ Cancer Epidemiology Unit, University Institute of Social and Preventive Medicine (IUMSP), Centre Hospitalier Universitaire Vaudois and University of Lausanne, Lausanne, Switzerland

${ }^{3}$ Federal Office of Meteorology and Climatology (MeteoSwiss), Payerne, Switzerland

*Address correspondence to:

Institute of Work and Health (IST)

Route de la Corniche 2

1066 Epalinges - Lausanne

Switzerland

Phone: $\quad$ +4121314 $\quad+4421$

Fax: $\quad+41213147430$

E-mail: antoine.milon@hospvd.ch

Keywords: Skin cancer, UV, Occupational exposure, Squamous cell carcinoma, Anatomical distribution, Outdoor workers, Chronic exposure

\section{Acknowledgements:}

This research was supported by the Swiss National Accident Insurance Organization (SUVA) and the French Agency for Environmental and Occupational Health Safety (Afsset)

\section{Conflicts of interest:}

The authors declare no competing financial interests 


\section{What is already known about the topic?}

Solar radiation is the most frequent occupational carcinogenic agent in many countries. It is also the main causative factor of skin cancer. However, skin cancer is barely recognized as an occupational disease due to a lack of data on the occupational contribution to the overall dose.

\section{What does this study add?}

This study aims to assess the contribution of occupational UV exposure in terms of annual (chronic) anatomical dose and acute events to the risk of squamous cell carcinoma (SCC) for various occupational scenarios. A numerical model (SimUVEx) was used to assess occupational and lunch break exposures, characterize exposure patterns and anatomical distribution. Risk of SCC was estimated from an existing epidemiological model.

\section{Possible reviewers:}

B.L.Diffey, Medical Physics Department, Dryburn Hospital, Durham DHI 5TW, U.K. b.l.diffey@ncl.ac.uk

T.L. Diepgen, Department of Social Medicine, Occupational and Environmental Dermatology, University Clinic of Heidelberg, Bergheimerstraße 58, Heidelberg 69115, Germany. thomas.diepgen@med.uniheidelberg.de

J.F. Doré, Centre de Recherche en Cancérologie de Lyon UMR Inserm U1052 - CNRS U5286 Centre Léon Bérard, 69373 LYON Cedex 08 France. dore@lyon.fnclcc.fr 


\section{ABSTRACT}

Background. Exposure to solar ultraviolet (UV) light is the main causative factor for skin cancer. Outdoor workers are at particular risk because they spend long working hours outside, may have little shade available and be bound to take their lunch at their workplace. Despite epidemiological evidence of a doubling in risk of squamous cell carcinoma in outdoor workers, the recognition of skin cancer as an occupational disease remains scarce.

Objective. To assess occupational solar UV doses and its contribution to skin cancer risk.

Methods. A numerical model (SimUVEx) was used to assess occupational and lunch break exposures, characterize exposure patterns and anatomical distribution. Risk of squamous cell carcinoma (SCC) was estimated from an existing epidemiological model.

Results. Horizontal body locations received 2.0-2.5 times more UV than vertical locations. Dose associated to lunch outdoor every day was similar to outdoor work one day per week but only half of a seasonal worker. Outdoor workers are associated with an increased risk of SCC but also of frequent acute episodes.

Conclusion. Occupational solar exposure contributes largely to the overall lifetime UV dose, resulting in an excess risk of SCC. The magnitude of the estimated excess in risk supports the recognition of SCC as an occupational disease. 


\section{INTRODUCTION}

Exposure to solar ultraviolet (UV) light is the main causative factor for skin cancer. Different patterns of exposure are associated with different types of skin cancer ${ }^{1}$. While cutaneous malignant melanoma (MM) and basal cell carcinoma (BCC) are predominantly related to intermittent and acute UV exposure, and often occur on occasionally exposed anatomical sites, squamous cell carcinoma (SCC) mainly results from chronic exposure, such as the exposure of outdoor workers, and prevails on unprotected body sites 2,3 .

In Europe, between 29 and $51 \%$ of subjects exposed to hazardous substances at workplace are exposed to UV radiation ${ }^{4}$. This makes solar radiation the most frequent occupational carcinogenic agent in many countries, particularly in regions where agriculture and fishing industries are important 5 , and affects, according to CAREX (CARcinogen EXposure) database, about 9 millions European workers ${ }^{6}$. Risk of solar UV overexposure during work is increased by the fact that activities usually take place regardless of the ambient irradiation, and repeated tasks performed in the same posture favor chronic overexposure of specific anatomical sites (e.g neck overexposure for a vineyard worker bent over the vine several hours per day). It is estimated that outdoor workers receive annually about $10 \%$ $(7 \%-18 \%)$ of the available ambient UV radiations, which represents two to nine times the UV dose that indoor workers get ${ }^{7}$. Depending on the job, the location and the season, much higher fraction of ambient UV radiation received have been documented in various occupational populations ${ }^{8-10}$. In Denmark, exposure of gardeners exceeded 10 standard erythemal doses (SED) for 160 days per year and in Australia, exposure of the hands of post mail delivery personnel exceeded 15 SED for 6 months ${ }^{11}$, doses well above the 0.3 SED recommended by the International Commission on Non-lonizing Radiation Protection (ICNIRP) ${ }^{12}$.

Despite compelling epidemiological evidence and the fact that many outdoor occupational activities lead to exposure to UV radiation above the recommended exposure limits, sun-induced skin cancer is not officially listed as an occupational disease, neither by the International Labour Office ${ }^{13}$ nor by national 
authorities. This situation leads to a large underestimation of the burden of SCC as an occupational disease. For instance, skin cancers represented in $20081 \%$ of all occupationally recognized cancers in Europe ${ }^{6}$. In Switzerland, where no less than 4500 SCC are diagnosed yearly ${ }^{14}$, only 3 cases of SCC were recognized as occupational disease between 2000 and $2007^{6}$.

A recent meta-analysis estimated a nearly twofold relative risk (RR) of SCC (RR: $1.8,95 \% \mathrm{Cl}: 1.4-2.2)$ for outdoor workers compared to indoor workers after adjusting for other SCC risk factors ${ }^{15}$. This doubling in risk meets in most countries the threshold for the recognition as an occupational disease, even though occupational disease recognition laws differ across countries ${ }^{16}$. Considering an hypothetical increase of $2.5 \%$ in SCC risk for every percent increase in UV dose received ${ }^{17}$, doubling the risk corresponds to a $40 \%(100 / 2.5)$ increase in total UV dose received. Thus, an occupational exposure leading to a $40 \%$ increase in UV dose could arguably come off a twofold risk of SCC for an outdoor worker compared to an indoor worker.

The contribution of occupational exposure to the total cumulative dose is central for the recognition of SCC as an occupational disease ${ }^{4}$. This is more complex for MM and BCC for which the occupational risk is often confounded by concurrent recreational exposure to UV ${ }^{15}$.

Exposure to UV radiation is a health concern at workplace which needs a better understanding of its determinants to improve UV protective means. Exposure data for different outdoor occupational groups are needed in order to perform risk analysis ${ }^{18}$. As suggested by Küttling and al. ${ }^{4}$, accurate models for determining the occupational exposure may also help workers to receive compensation by the statutory accident insurance.

This study aims to assess the contribution of occupational UV exposure in terms of annual (chronic) anatomical dose and acute events to the risk of SCC for various occupational scenarios. A validated simulation tool ${ }^{19}$ was used to obtain daily and yearly UV doses. 


\section{MATERIAL AND METHODS}

\section{Exposure model and data source}

The SimUVEx model has been used to assess solar UV. SimUVEx uses 3D computer graphics techniques to compute anatomical UV doses on the basis of postural information and ambient UV (erythemally-weighted) measurements. The model takes into account body surface inclination and orientation to sun as well as the shading from other body parts. SimUVEx results can be expressed either numerically, as anatomical doses $\left(\mathrm{J} / \mathrm{m}^{2}\right)$ over 45 body sites, or graphically, using a colored virtual manikin (false color scale). The principles and a validation of the SimUVEx model in field conditions have been detailed elsewhere ${ }^{19}$.

Five input parameters are required by the model: direct irradiance $\left(\mathrm{W} / \mathrm{m}^{2}\right)$, diffuse irradiance $\left(\mathrm{W} / \mathrm{m}^{2}\right)$, ground reflected irradiance $\left(\mathrm{W} / \mathrm{m}^{2}\right)$ and sun position (defined by its azimuth $\mathrm{p}(\mathrm{t})$ and zenith $\mathrm{d}(\mathrm{t})$ angles). Ambient UV irradiance data were obtained from the MeteoSwiss Payerne station $\left(46.8^{\circ} \mathrm{N}, 6.9^{\circ} \mathrm{E}\right.$, altitude $491 \mathrm{~m}$ ), which is part of the Baseline Surface Radiation Network of the World Meteorological Organization, World Climate Research Program ${ }^{20}$. Ambient UV measurements are performed every minute at this facility using broadband UV radiometers (biometer $501 \mathrm{~A}$ by Solar Light) with filters mimicking the erythemal response (erythemally-weighted irradiance) ${ }^{21}$. These broadband radiometers undergo strict quality assurance procedures including regular calibrations traceable to the European Ultraviolet Calibration Center 22 and the overall uncertainty of the measurement is estimated at $10 \%$.

Ground irradiance data collected for the entire year 2012 were used in this study $\left(525^{\prime} 600\right.$ measurements). Due to maintenance of the measuring device, $0.9 \%, 1.4 \%$ and less than $0.1 \%$ missing/aberrant values were recalculated for direct, diffuse and reflected measurements, respectively, using ground global irradiance. Data were treated and analysed using Stata/IC 12.0 (StataCorp LP, Texas, USA).

\section{Exposure scenarios}


A manikin was placed standing up, arms down and rotating on itself at $24 \%$ min (complete revolution time of 15 minutes). This posture predominates for example among construction workers where activities typically require frequent movements without a specific orientation ${ }^{23}$. The computed daily doses assumed an unprotected skin so that results indicate upper dose estimates.

Two types of doses were computed for each day of the year 2012, leading to 732 simulation runs: (1) workday doses, defined as 8-12 am and 1-5 pm exposure and (2) lunch breaks doses, defined as exposure between 12 am and $1 \mathrm{pm}$.

The dataset generated during simulations was used to establish cumulative yearly doses corresponding to exposure situations for different body locations. For convenience, semi-quantitative exposures categories were used (high, moderate and low) to describe occupational and lunch exposure.

As shown in Table 1, exposure bands are defined in terms of number of days per week or month spent outdoor. These exposure bands cover a variety of occupational activities, from individuals working mostly indoors (e.g. office work taking their lunch outside) to full time outdoor workers (e.g. construction work, farming). A one day per week exposure has been considered for intermediate situations (moderate occupational exposure). A typical example of moderate exposure is a "white-collar" in the construction sector supervising outdoor work on a regular basis. A seasonal scenario has also been considered and defined as the same amount of time spent outdoor as a moderate exposure scenario (416 h/year for occupational activity and 52h/year for lunch) but concentrated during the summer holiday period (from $6^{\text {th }}$ of July to $26^{\text {th }}$ of August).

Table 1

Distributions of daily doses and cumulative yearly doses were computed for various anatomical parts. The cumulative yearly doses were expressed either in SED or exposure ratios (ER) corresponding to 
the percent of ambient irradiation received. The latter indicator is of interest as it is independent of the geographical location where the measurement is performed. The frequency of acute events, expressed as a number of days/year for which a dose threshold was exceeded, was also computed.

\section{Estimating squamous cell carcinoma risk}

The model first proposed by Schothorst and Slaper 24,25 was used to estimate the influence of occupational outdoor activity and lunch break on the risk of squamous cell carcinoma (SCC). In this model, the risk of SCC is expressed as a function of age and cumulative UV dose:

$R i s k \propto(a g e)^{\alpha} x\left(U V_{t o t}\right)^{\beta}$

Where $\alpha$ and $\beta$ are the respective age-dependent and biological amplification factor constants and $U V_{\text {tot }}$ is the cumulative UV dose received from occupational exposure, lunch exposure and recreational exposure (integrating residential exposure and exposure during recreational activities).

From equation 1, we can express the relative risk (RR) of SCC for two people of the same age, exposed to two different cumulative UV doses ( $A$ and $B$, respectively) as:

$\mathrm{RR}_{\mathrm{age}=\mathrm{T}}=\frac{\operatorname{Risk}_{\mathrm{B}, \mathrm{T}}}{\operatorname{Risk}_{\mathrm{A}, \mathrm{T}}}=\left(\frac{\mathrm{UV}_{\text {tot }, \mathrm{B}} \text { at age } \mathrm{T}}{\mathrm{UV}_{\text {tot }, \mathrm{A}} \text { at age } \mathrm{T}}\right)^{\beta}$

Relative risk of SCC was estimated at 60 years old with an outdoor work history of 25 years (cumulative UV dose B), the reference being an indoor worker who took is lunch indoor (cumulative UV dose A). A value of 2.5 was considered for the biological amplification factor ${ }^{25}$.

The cumulative UV dose at age $T=60$ is expressed as the sum of exposures during work and lunch during y years of occupational activity and recreational time from 0 to $\mathrm{T}$ :

Cumulative UV dose B $=\sum_{t=0}^{60} U V_{\text {tot }}=\sum_{y=t}^{t+25}\left(U V_{\text {occ }}+U V_{\text {lunch }}\right)+\sum_{t=0}^{60} U V_{\text {recr }}, \forall y \in[25,35]$ 
And

Cumulative UV dose $\mathrm{A}=\sum_{t=0}^{60} U V_{\text {tot }}=\sum_{t=0}^{60} U V_{\text {recr }}$

UV occ and UV lunch were obtained with SimUVEx while $U V_{\text {recr }}$ was based on a behavioral model applied to time-microenvironment-activity-diary data collected in a large European study (Expolis) ${ }^{26,27}$. An annual dose of 297 SED for the face was used as a reference for recreational exposure. This value corresponds to the recreational dose for office workers in Milan, the surveyed Expolis location where annual ground irradiance was the closest to Payerne (6941 SED and 6296 SED respectively). The sensitivity of the model to the recreational dose was assessed by varying the recreational dose (297 SED) by $10 \%(267.3-326.7$ SED).

The exposure situations and categories of exposure frequencies considered are summarized in table 1. As the annual recreational UV dose has been shown to be independent of age ${ }^{28}$, the same recreational dose was considered during the 60 years. The occupational UV dose was considered constant during the 25 years of work according to the chosen scenario.

\section{RESULTS}

\section{Annual doses}

The annual UV doses and ER for the face, back of the neck, shoulder, top of shoulders and forearm related to various occupational exposure scenarios are given in Table 2. These anatomical sites (Figure 1) were of special interest because they are often left uncovered, have various orientations and have been associated with BCC and SCC (at least for the face and neck). Computed doses provided upper bound limits as an unprotected skin was assumed for the whole year.

Fig. 1 
Table 2

Face exposure of full time outdoor workers (lunch excluded) was of 1604 SED, corresponding to a mean of 5.8 SED per working day. Higher doses were observed in anatomical sites more horizontallyoriented, such as the shoulders (2219 SED) the neck (2373 SED) or the top of shoulders (3438 SED). On average, the most horizontally-oriented site considered (top of shoulders) received consistently 2.02.1 times more of the ambient irradiation than the most vertically-oriented one (face) during work time periods. During the lunch period (12 am-1 pm), when the sun is at its highest zenithal angle, this ratio only marginally increases with the top of shoulder receiving 2.0-2.2 times more ambient irradiation than the face.

As expected, seasonal workers were more exposed than year-round workers due to the elevated ambient irradiation in summer. Anatomical doses in seasonal workers were about twice the anatomical doses endured by year-round workers exposed for the same cumulative duration (corresponding to moderate occupational activity). The difference in exposure between horizontally and vertically-oriented body locations increased with decreasing zenithal angle. The top of shoulder received 2.3-2.5 times more ambient irradiation than the face for a seasonal activity.

\section{Short-term exposure}

Daily doses (8am-12am/1pm-5pm) were used in this study as an indicator of acute exposure. Daily doses above the minimum erythemal dose for an average skin phototype were considered as overexposures. Typically, the minimum erythemal doses for skin types II and III, the most common phototypes in Caucasian populations, are respectively 2.5 and 3.0 SED ${ }^{29}$. The monthly distribution of daily doses for different body locations is presented in Figure 2. Similarly to ambient irradiation, personal exposure varies substantially within a year, exhibiting a typical bell-shaped curve. The profile was 
pronounced for horizontally-oriented anatomical sites: the top of shoulders received daily doses up to 37 SED. A strong attenuation was observed for vertically-oriented locations, such as the face, which exhibited a maximum of 15 SED.

The ratio in annual doses previously described between horizontally and vertically-oriented anatomical sites appears to be time-dependent. The top of shoulders was about 1.7 more exposed than the face in the middle of winter (December-January) and about 2.3 times more exposed in early summer (June July). Exposure variability appears also to be greater for horizontally-oriented anatomical sites.

Overall, predicted daily doses for unprotected skin were found to be high for all anatomical sites and, except in winter, above the minimal erythemal doses for skin types II and III.

Fig. 2

Episodes of acute exposures were examined more closely by computing the number of days per year for which a given dose could be exceeded (Figure 3).

Fig. 3

For both the face and the top of shoulders, daily dose exceeded the minimal erythemal doses for skin types II and III more than 200 days a year. Opportunities for overexposure above 10 SED occurred 80 days/year for the face and around 190 days/year for the top of shoulders. No opportunity for overexposure above 20 SED was observed for the face. The top of shoulders was potentially above 20 SED on about 90 days a year.

\section{Relative risk of squamous cell carcinoma}

The estimated RR of SCC for the face is presented in Table 3. The RR compares outdoor workers with various exposure patterns to an individual with the same recreational activities (thus the same 
recreational UV dose) but with no occupationally-related exposure. The reference value (RR of 1.0, bottom-right of table 3) corresponds to a non-exposed individual, such as an indoor worker, that does not take his/her lunch outside. The sensitivity analysis indicated a maximum change of $22 \%$ in RR for $10 \%$ variation in recreational dose around the reference value of 297 SED.

Table 3

Because the exposure model assumes long working hours outdoor, no shade, no protective clothing, no tanning effect, RR estimates should be considered as upper values. Still, only a few scenarios lead to less than a twofold RR of SCC. In particular, having an activity with high or moderate occupational exposure or a summer outdoor occupation over 25 years confers a substantially increased risk of SCC, regardless of exposure during the $12 \mathrm{am}-1 \mathrm{pm}$ lunch break. Apart for seasonal workers, frequent outdoor lunches (1-5 times/week over a whole year) contribute materially to the increase in SCC risk, which is consistent with prevention messages advocating avoidance of peak sun exposure. 


\section{DISCUSSION}

Cumulative occupational dose and lunch time exposure dose. When unprotected against solar radiation, outdoor workers could be exposed to high UV doses, up to $25.5-54.6 \%$ of the annual ambient irradiance depending on the anatomical site. In practice, this potential exposure is mitigated by occasional shade (e.g. surrounding trees or buildings, indoor working periods), protection from clothing or absence from worksite (e.g. traveling, sick leave), factors that were not accounted for in our model. Comparing results across studies is difficult due to discrepancies in study design, geographical location, body sites and doses types. Annual doses previously reported for regular outdoor work varies between 54 and 669 SED on the wrist of gardners in Danemark ${ }^{28}$, around 1097 SED on the side of the hands of mountain guides in the Alps 30,1920 SED on the chest, 3880 SED on the hands and 2830 SED on the back of postmen in Australia (ambient $=15100$ SED) ${ }^{11}$. These observations suggest that a realistic scenario would be between the high and moderate outdoor exposure situations considered (Table 1).

For moderate and high occupational exposure scenarios, the elevated UV doses emphasize the need of targeted prevention among outdoor workers. Moreover, lunch time exposure was estimated separately from work time exposure. Whether lunch time exposure should be considered as work-related or not depends on the context. An office worker may choose to have its lunch break on an open terrace, while a building worker on a remote construction site may have no other choice but to take his lunch break onsite, where shading is not necessarily available. The former exposure is not intrinsically occupationally-related whereas the latter exposure is work-related and should be added to the work time exposure when estimating a risk. Our estimates suggest that moderate and high lunch exposure intensities (at least once a week), which amounted to $1.0-2.1 \%$ and $4.9-10.9 \%$ of annual ambient irradiance, respectively, contribute significantly to the annual dose. The UV yearly dose of workers taking their lunch outdoors on every workday was comparable to the exposure dose of someone working outdoor one day per week. These results support the importance of seeking shade during 
"peak" periods (typically $11 \mathrm{am}$ to $3 \mathrm{pm}$ ) as advocated in public prevention messages. However, such a recommendation seems hardly practicable at some worksites.

Anatomical variability. Annual exposure of horizontally-oriented body parts was found to be 2.0-2.5 times higher than that of vertically-oriented body parts. This anatomical variability concurs with previous studies. According to Wright et al., vertical surfaces received $13-76 \%$ of the exposure of the vertex of the head with an average of $38 \%$ while horizontal surfaces received $47-82 \%$ with an average of $60 \% 31$. Moreover, a ratio of 2 in average values received for vertical (38\%) and horizontal $(75 \%)$ surfaces respectively were also found by Diffey ${ }^{32}$. The fact that diffuse radiation is the major contributor to the annual exposure doses ${ }^{33}$ explains probably the limited anatomical variability found in this study. It should be pointed out however that anatomical variability is often greater with shorter time exposure (e.g. daily exposure) or short period of exposure during the day (e.g. lunch period). Sun position and thus posture and orientation to the sun are indeed key factors in the anatomical distribution of exposure. On the one hand, vertically-oriented body parts receive a larger amount of the direct normal irradiance when the sun is low (high zenithal angle), such as early or late during the day or early or late in the year. On the other hand, direct sunlight goes through a larger amount of ozone layer when the sun is low corresponding to a higher UV absorption. The two effects may compensate. For horizontal surface, the zenithal angle effect is reversed, but the radiation atmospheric path effect is still the same and the two effects add up.

Most mathematical model assessing cumulative doses use ambient exposure data (UV index for example) and ambient exposure fraction ${ }^{18}$. This approach should be used carefully, particularly when estimating anatomical exposure. .SimUVEx does take into account shaded body areas and can be used for different postures.

Acute events. Most of the year (>200 days) the daily dose endured by unprotected skin potentially exceeded the minimal erythemal doses for skin types II and III. Opportunities for severe sunburns are 
frequent for outdoor workers. In practice, sunburns occur noticeably less frequently because the simplifying hypotheses of the model (long working time outdoor, without shading or protective clothing, no tanning attenuation effect) lead to upper exposure estimates.

The high frequency of potential sunburns suggests however that high chronic doses are also associated with a high number of opportunities for acute, intermittent overexposure. While sunburn (acute exposure) is a risk marker for MM and possibly $\mathrm{BCC}$, chronic exposure has been associated with SCC and, to a lesser extent, BCC. Our results underline the somewhat arbitrary distinction made between chronic and intermittent exposure, a finding which questions the potential contribution of occupational exposure to MM.

Occupational sun exposure and risk of SCC. The risk model used for estimating the risk of SCC 25 , though widely applied and supported by epidemiological evidence, implicitly assumes constant annual exposure. Use of a more elaborate model that accounts for varied patterns of annual occupational exposure over time (such as proposed by Slaper and van der Leun for melanoma ${ }^{25}$ ) reduces overall the magnitude of RR of SCC but did not affect materially the gradients observed in RR with frequency of outdoor lunch and outdoor occupational activity (data not shown). These observations further indicate that albeit our results represent in absolute terms an upper bound of UV exposure doses, they seem to reflect fairly well the relative variations in risk according to occupational UV doses.

Doubling in risk meets in most countries the threshold for the recognition as an occupational disease. Indeed, all occupational scenarios, including seasonal work, led to an increased risk of SCC higher than twofold and higher than $40 \%$ of occupational contribution on the annual dose, except when working outdoor only 1 day a month with lunch break taken outdoors no more than one day per working week.

Again, a moderate exposure scenario is suggested to be the most common among outdoor workers when compared to SCC estimates obtained by Vishvakarman and Wong ${ }^{18}$. 
These results suggest that occupational exposure is a major contributor to SCC in outdoor workers and emphasized that (1) the recognition of SCC as occupational disease for this population should be facilitated and systematized, and (2) specific prevention messages towards chronic sun exposure at work are needed.

As expected, seasonal workers are particularly at risk since ambient exposure peaks during the summer period. Behavior of seasonal workers toward prevention strategies might be different from regular outdoor workers and could result in a potential increased risk of skin cancer. Prevention messages for outdoor workers should recognize these 2 types of working population and include information about consequences of acute and intermittent exposure during work period.

This study shows the necessity of more accurate recreational exposure data as well as accurate estimation of the duration of occupational exposure. It also presents the use of an original tool to produce data that can help physicians in the recognition of skin cancers as an occupational disease. The approach used in this study could serve as a first estimate to evaluate the occupational contribution to the lifetime UV dose in case of a claim for recognition of a skin cancer replacing complicated tabulations. By taking into account exposure patterns during childhood and recreational activities (in term of corresponding UV dose), the relative part of the occupational cumulative dose can be estimated. A matrix is a convenient way to combine the different situations of exposure. It could support occupational physicians in estimating the contribution of work-related exposures and support decision making in occupational skin cancer recognition. It could also help to identify the high-risk occupational activities to implement prevention strategies to reduce SCC incidence in the occupational outdoor workers population.

\section{CONCLUSION}

Occupational activity is a major contributor to the overall UV doses in outdoor workers. The work-related doses calculated in this study clearly indicate an elevated risk of SCC in high and moderate 
occupational exposure scenario compared to an indoor worker in high and moderate exposure scenario. Additionally, the anatomical distribution of the dose indicates a non-uniform exposure of the body even when considering a simple posture. These results question the relevancy of using the UV index as a prevention tool. Regular sun exposures also appear to favor increased episodes of acute exposure, which raise concerns about the potential contribution of occupational UV exposure to other forms of skin cancers. 


\section{REFERENCES}

1 Armstrong BK, Kricker A. The epidemiology of UV induced skin cancer. J Photochem Photobiol B 2001; 63: 8-18.

2 Gallagher RP, Lee TK. Adverse effects of ultraviolet radiation: A brief review. Biophysics and molecular biology 2006; 92: 119-31.

3 MacKie RM. Long-term health risk to the skin of ultraviolet radiation. Progress in Biophysics and Molecular Biology 2006; 92: 92-6.

4 Kütting B, Drexler H. UV-induced skin cancer at workplace and evidence-based prevention. Int Arch Occup Environ Health 2010: 843-54.

5 Kauppinen T, Toikkanen J, Pedersen D et al. Occupational exposure to carcinogens in the European Union. Occupational and Environmental Medicine 2000; 57: 10-8.

6 Eurogip. Work-related cancers: what recognition in Europe? In: Survey report: Eurogip, 2010: 52.

$7 \quad$ Godar DE. UV doses worldwide. Photochem Photobiol. 2005; 81: 13.

8 LarkÖ O, Diffey BL. Natural UV-B radiation received by people with outdoor, indoor, and mixed occupations and UV-B treatment of psoriasis. Clinical and Experimental Dermatology 1983; 8: 279-85.

9 Hammond V, Reeder Al, Gray A. Patterns of real-time occupational ultraviolet radiation exposure among a sample of outdoor workers in New Zealand. Public Health 2009; 123: 182-7.

10 Thieden E, Collins SM, Philipsen PA et al. Ultraviolet exposure patterns of Irish and Danish gardeners during work and leisure. British Journal of Dermatology 2005; 153: 795-801.

11 Vishvakarman D, Wong JCF, Boreham BW. Annual occupational exposure to ultraviolet radiation in Central Queensland. Health Physics 2001; 81: 536-44. 
12 International Commission on Non-ionizing Radiation Protection (ICNIRP). Guidelines on limits of exposure to ultraviolet radiation of wavelengths between $180 \mathrm{~nm}$ and $400 \mathrm{~nm}$ (incoherent optical radiation). Health Physics 2004; 87: 171-86.

13 ILO. List of occupational diseases (revised 2010). In: Identification and recognition of occupational diseases: criteria for incorporating diseases in the ILO list of occupational diseases, Vol. No. 74. Geneva: International Labour Office, 2010.

14 Bulliard JL, R.G. P, Levi F. Epidemiology of epithelial skin cancers. Rev Med Suisse 2009; 5: 882-8.

15 Schmitt J, Seidler A, Diepgen TL et al. Occupational ultraviolet light exposure increases the risk for the development of cutaneous squamous cell carcinoma: a systematic review and metaanalysis. British Journal of Dermatology 2011; 164: 291-307.

16 Miettinen OS. Proportion of disease caused or prevented by a given exposure, trait or intervention. American Journal of Epidemiology 1974; 99 : 7.

17 Kelfkens G Fau - de Gruijl FR, de Gruijl Fr Fau - van der Leun JC, van der Leun JC. Ozone depletion and increase in annual carcinogenic ultraviolet dose. Photochem Photobiol. 1990; 52: 4.

18 Vishvakarman D, Wong JCF. Description of the use of a risk estimation model to assess the increased risk of non-melanoma skin cancer among outdoor workers in Central Queensland, Australia. Photodermatol Photoimmunol Photomed 2003; 19: 81-8.

19 Vernez D, Milon A, Francioli $L$ et al. A Numeric Model to Simulate Solar Individual Ultraviolet Exposure. Photochemistry and Photobiology 2011; 87: 721-8.

20 Ohmura A, Dutton EG, Forgan B et al. Baseline Surface Radiation Network (BSRN): New precision radiometry for climate research. Bull.Am.Meteorol.Soc. 1998; 79: 2115-36. 
21 McKinlay AF, Diffey BL. A reference action spectrum for ultra-violet induced erythema in human skin. In: Human Exposure to Ultraviolet Radiation: Risks and Regulations. (Passchier WF, Bosnjakovich BFM, eds): Elsevier Science Ltd, 1987: 83-7.

22 Hülsen G, Gröbner J. Characterization and calibration of ultraviolet broadband radiometers measuring erythemally weighted irradiance. Appl.Opt. 2007; 46: 5877-86.

23 Milon A, Sottas PE, Bulliard JL et al. Effective exposure to solar UV in building workers: influence of local and individual factors. Journal of Exposure Science and Environmental Epidemiology 2007; 17: 58-68.

24 Schothorst A, Slaper H, Schouten R et al. UVB doses in maintenance psoriasis phototherapy versus solar UVB exposure. Photodermatology 1985; 2: 8.

25 Slaper H, Velders GJM, Daniel JS et al. Estimates of ozone depletion and skin cancer incidence to examine the Vienna convention achievements. Nature 1996; $\mathbf{3 8 4 : 3 .}$

26 Dadvand $\mathrm{P}$, Basagana $\mathrm{X}$, Barrera-Gomez $\mathrm{J}$ et al. Measurement errors in the assessment of exposure to solar ultraviolet radiation and its impact on risk estimates in epidemiological studies. Photochem Photobiol Sci. 2011; $10: 7$.

27 Diffey B. A Behavioral Model for Estimating Population Exposure to Solar Ultraviolet Radiation†. Photochemistry and Photobiology 2008; 84: 371-5.

28 Thieden E, Philipsen PA, Heydenreich J et al. UV Radiation Exposure Related to Age, Sex, Occupation, and Sun Behavior Based on Time-Stamped Personal Dosimeter Readings. Arch Dermatol 2004; 140: 197-203.

29 Dornelles S, Goldim J, Cestarl T. Determination of the Minimal Erythema Dose and Colorimetric Measurements as Indicators of Skin Sensitivity to UV-B Radiationף. Photochemistry and Photobiology 2004; 79: 540-4.

30 Moehrle M, Dennenmoser B, Garbe C. Continuous long-term monitoring of UV radiation in professional mountain guides reveals extremely high exposure. Int J Cancer 2003; 103: 775-8. 
31 Wright C, Diab R, Martincigh B. Anatomical distribution of ultraviolet solar radiation. South Afr J Sci 2004; 100: 498-500.

32 Diffey BL. Solar ultraviolet radiation effects on biological systems. Review in Physics in Medicine and Biology 1991; 36: 299-328.

33 Vernez D, Milon A, Vuilleumier $L$ et al. Anatomical exposure patterns of skin to sunlight: relative contributions of direct, diffuse and reflected ultraviolet radiation. British Journal of Dermatology 2012; 167: 383-90. 
Table 1. Categorization of exposure situations and corresponding exposure frequencies, a) whole year and b) seasonal occupational activity

a)

\begin{tabular}{llllr}
\hline Activity & Exposure period & Exposure intensity & Exposure frequency & Hours/year \\
\hline Occupational & $8-12 \mathrm{am}+1-5 \mathrm{pm}$ & High & 5 days/week & 2088 \\
& & Moderate & 1 day/week & 416 \\
& & Low & 1 day/month & 96 \\
\hline Lunch & $12 \mathrm{am}-1 \mathrm{pm}$ & High & 5 days/working week & 261 \\
& & Moderate & 1 day/working week & 52 \\
& & Low & 1 day/ working month & 12 \\
\hline
\end{tabular}

b)

\begin{tabular}{llllr}
\hline Activity & Exposure period & Exposure intensity & Exposure frequency & Hours/year \\
\hline Occupational & 8-12 am +1-5 pm & Seasonal & 6Jul12 to 26Aug12 & 416 \\
\hline Lunch & $12 \mathrm{am}-1 \mathrm{pm}$ & High & 5 days/working week & 52 \\
& & Moderate & 1 day/working week & 8 \\
& & Low & 1 day/ working month & 2 \\
\hline
\end{tabular}


Table 2. Annual UV dose by specific body site and exposure frequency. Results are given in SED (1 SED = $100 \mathrm{~J} / \mathrm{m}^{2}$ ) and as ER (in \%) for a) year-round activity and b) seasonal activity

\begin{tabular}{|c|c|c|c|c|c|c|}
\hline \multicolumn{2}{|l|}{ a) } & \multicolumn{5}{|c|}{ Yearly dose [SED] (ER \%) } \\
\hline Activity & $\begin{array}{l}\text { Exposure } \\
\text { intensity }\end{array}$ & Face & $\begin{array}{c}\text { Forearm } \\
\text { (right) }\end{array}$ & $\begin{array}{l}\text { Shoulder } \\
\text { (right) }\end{array}$ & Neck back & Top of shoulders \\
\hline \multirow[t]{3}{*}{ Occupational } & High & $1604(25.5)$ & $1696(26.9)$ & $2219(35.2)$ & $2373(37.7)$ & $3438(54.6)$ \\
\hline & Moderate & $311.0(4.9)$ & $329.3(5.2)$ & $427.3(6.8)$ & $457.8(7.3)$ & $655.0(10.4)$ \\
\hline & Low & $76.2(1.2)$ & $80.6(1.3)$ & $103.8(1.6)$ & $111.1(1.8)$ & $157.3(2.5)$ \\
\hline \multirow[t]{3}{*}{ Lunch } & High & $311(4.9)$ & $327.3(5.2)$ & $433.7(6.9)$ & $464.8(7.4)$ & $683.8(10.9)$ \\
\hline & Moderate & $62.1(1.0)$ & $65.3(1.0)$ & $85.5(1.4)$ & $91.5(1.5)$ & $132.8(2.1)$ \\
\hline & Low & $14.9(0.2)$ & $15.8(0.3)$ & $20.2(0.3)$ & $21.6(0.3)$ & $30.3(0.5)$ \\
\hline
\end{tabular}

b)

\begin{tabular}{llccccc}
\hline Activity & $\begin{array}{l}\text { Exposure } \\
\text { intensity }\end{array}$ & Face & $\begin{array}{c}\text { Forearm } \\
\text { (right) }\end{array}$ & $\begin{array}{c}\text { Shoulder } \\
\text { (right) }\end{array}$ & Neck back & Top of shoulders \\
\hline Occupational & Seasonal & $578.1(9.2)$ & $612.2(9.7)$ & $824.0(13.1)$ & $880.3(14.0)$ & $1323(21.0)$ \\
\hline Lunch & High & $99.8(1.6)$ & $105.4(1.7)$ & $145.5(2.3)$ & $156.6(2.5)$ & $240.6(3.8)$ \\
& Moderate & $14.0(0.2)$ & $14.7(0.2)$ & $20.5(0.3)$ & $22.3(0.4)$ & $34.8(0.6)$ \\
& Low & $2.0(0.05)$ & $2.0(0.05)$ & $2.8(0.07)$ & $3.2(0.1)$ & $4.8(0.1)$ \\
\hline
\end{tabular}


Table 3. Relative risk of SCC for the face at age 60 due to an outdoor occupational activity during 25 years. RR of SCC and RR range corresponding to $+/-10 \%$ of the recreational dose.

Outdoor occupational activity

$\operatorname{RR}$ of SCC $[-]([+10 \%]-[-10 \%])$

\begin{tabular}{llccccc} 
& & High & Moderate & Seasonal & Low & None \\
\hline \multirow{nnyyyyy}{*}{$\begin{array}{llcl}\text { Outdoor } \\
\text { lunch }\end{array}$} & High & $26.1(22.0-31.7)$ & $4.8(4.3-6.9)$ & $5.3(4.7-6.1)$ & $3.0(2.7-3.3)$ & $2.5(2.3-2.7)$ \\
& Moderate & $20.3(17.3-24.5)$ & $2.9(2.6-3.8)$ & $4.5(4.1-5.1)$ & $1.6(1.5-1.6)$ & $1.2(1.2-1.3)$ \\
& Low & $19.4(16.4-23.3)$ & $2.6(2.4-3.3)$ & $4.4(4.0-5.0)$ & $1.4(1.3-1.4)$ & $1.1(1.0-1.1)$ \\
& none & $19.0(16.2-22.9)$ & $2.5(2.3-3.1)$ & $4.4(4.0-5.0)$ & $1.3(1.3-1.3)$ & $1.0(1.0-1.0)$ \\
\hline
\end{tabular}


Figure 1. View of the numeric manikin and location of the anatomical sites investigated. The relative surface of each site is expressed as a percentage of total body surface (about $2 \mathrm{~m}^{2}$ ).

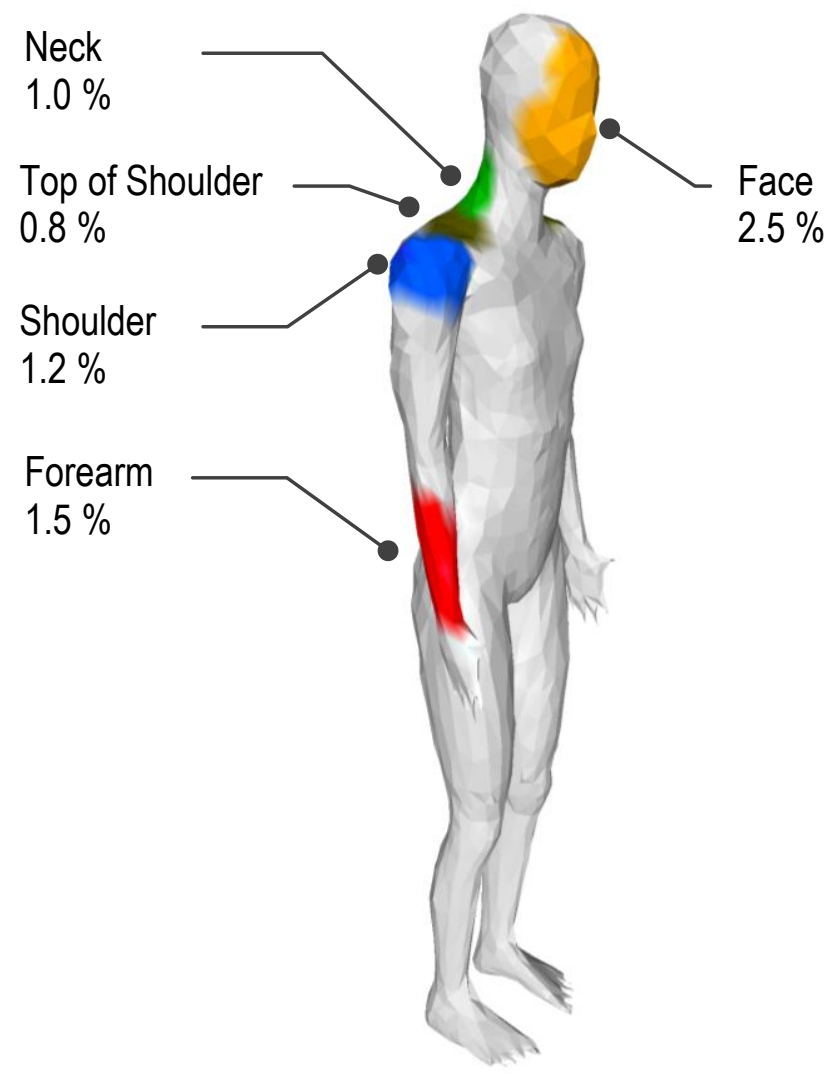


Figure 2. Box plot shows the median (central line), the interquartile range (box), and the range of the daily distribution of UV dose (whiskers) for face and top of shoulders.

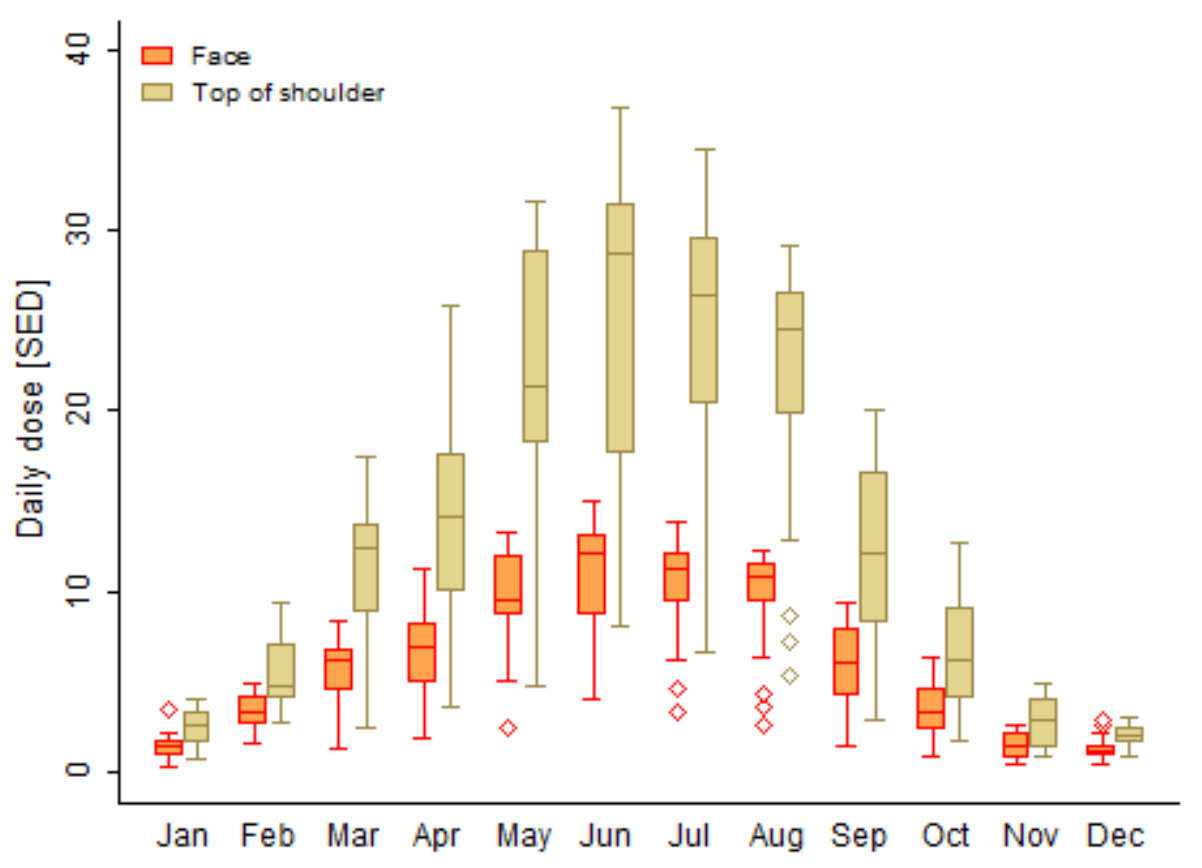


Figure 3. Number of days per year for which a given daily dose (in SED) is exceeded for two anatomical sites (assuming an 8 am to 5 pm daily exposure).

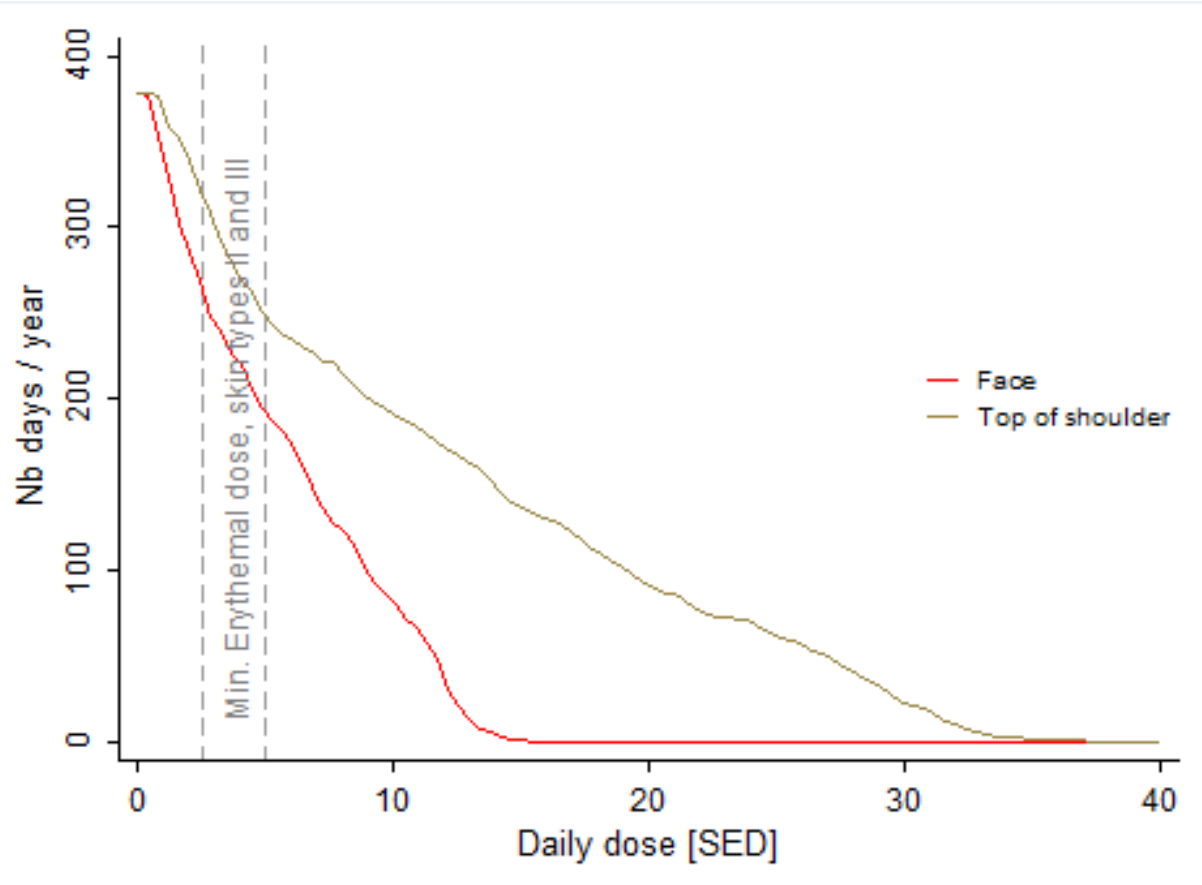

